\title{
THE CONTRIBUTION OF TEMPORARY ASSEMBLAGE TOWARDS SENSE OF PLACE: A STUDY IN ALUTH NUWARA SACRED AREA, SRI LANKA
}

\author{
WIJESEKARA.W.W.G.M.I.U. ${ }^{1} \&$ MUNASINGHE.J.N. ${ }^{2}$ \\ 1,2Department of Town \& Country Planning, University of Moratuwa, Katubedda, Sri Lanka \\ 1indunilwijeskara@gmail.com, ${ }^{2}$ jagathnm@uom.lk
}

\begin{abstract}
Sense of place' is a complex phenomenon emerging from the associations of the inhabitants, the values they attribute on the built environment, and the manner in which they behave in that place. Every built environment gets its form and character out of a composite of both the permanent structures and temporary assemblage. This is mostly evident in living sacred built environments where impermanent and 'supposed to be non-lasting' structures assembled for temporal benefits, amidst formally arranged permanent spaces, play a significant role in making them functional places. However, the existence of temporary physical assemblage has throughout been considered as 'problematic' in formal institutional planning, in spite of the utility, character and the sense of place that they add to day-to-day livedin environments. In a context, where the available studies are limited, this paper discusses on these temporary interventions and their impact in experiencing of places, in-order to widen the awareness and in-depth understanding of planners, urban designers and the authorities, who are responsible for the making of sustainable built environments. The paper first presents a review of the existing literature in order to identify a suitable theoretical framework to study the impacts of temporal assemblage on sense of place. Second, employing the conceptual framework profound in 'Bennett's six triads', it presents the study on the mutual transactive relationships between the activity spaces and the behavior patterns of the inhabitants, as observed by the authors, in Aluth Nuwara Devala sacred area in Sri Lanka. It emphasizes the manner in which the temporary assemblage, within the formal built environment, impacts the settings, values and the behaviors of the inhabitants and thereby form the sense of place. The study highlights that temporary assemblage adds sense to places not only by their presence but also by changing people's behaviors.
\end{abstract}

Keywords: Temporary assemblage, Sense of Place, Bennett's six triads

\section{Background}

"In a world where planners look after the plans, architects look after the buildings, landscape architects attend to the landscapes, and traffic planners provide for the traffic it has become increasingly apparent that no one is specifically asked to look after the people"

(Gehl, 2010).

This famously quoted Jang Gehl's statement leads to query as to what is there to be looked after of people, when there are plans, designs and projects for their benefit. It is at this juncture that one would also recall Edward Relph's (1976) argument that designers who pay no regard to sense of place, tries to destroy authentic places, and make inauthentic ones. Sense of place is a complex phenomenon associated with peoples' inhabiting of places. Even though it has yet to be defined with some level of precision, it involves people, the values they attribute in the built environment and the manner in which they behave in the physical environment of the place. A place is formed and shaped by its inhabitants through various means to embody meanings, supposedly communicated to its users (Rapoport, 1977) and in turn, inhabitants' comprehension and behavior are shaped by the places (Shinbira, 2012). It is this mutual interaction process between inhabitants and their socio-spatial environment that can be broadly understood as underlying in the development of sense of place. 
People gain sense of place by various means attributed in built environment. Temporary assemblage is one of them. Formally built environments, organized on dominant themes of architecture and built complying with widely agreed 'formal' planning and design principles, are reshaped by people with 'informal' temporary assemblage.

Temporary assemblage can be defined as short-term interventions in permanent built environments that enable makeshift use of spaces. Scholars suggest that the "use of temporary assemblage offer the opportunity to study unconventional solutions and experiment with functions, allowing quick and flexible answers and circumventing some bureaucratic planning procedures" (Bertino et al., 2019). However, not those temporary assemblages are always welcomed by formal planning authorities, and it is a matter of debate as to whether the temporary assemblage should be accommodated within formally planned environments. In current discourse while many argue against them, there are also arguments that they (temporary assembled spaces) go beyond quick and flexible structures for nurturing places; they also lend freedom to promote artistic installations like allotment gardens, adaptive reuse in historic and abandoned buildings, regenerating sites, retail installations, outdoor functions, mimicking of traditional events and many other activities.

While the appropriateness of the temporary assembles in the planned environments are in debate, their presence in heritage areas is mostly discussed as problematic, for the reason that "the sense of place in heritage sites can be achieved only if such heritage can remain intact and preserved whilst accommodating for new development" (Shinbira, 2012). This resistance of governing authorities is at peak when important sacred places and their peripheral environs are occupied by street vendors and their stalls causing visual inconsistencies and practical inconvenience to their users.

The system of linking historic environments, sense of place and social capital are not yet fully known (Graham et al., 2009), but well-preserved historic environments support distinctive character, sense of place and the continuity of identity through time. Hence, all temporary assembling said to have contributed negatively to the visual quality and the cleanliness of the places because of the 'disorganized' arrangements. The challenge then, is to ascertain how people value and understand historical environment and act on reshaping them to gain sense of place, as against formal planning arrangements launched by the institutions.

In this context, this study, from its inception, takes a positive attitude towards temporary assemblage and attempts to elaborate the manner, in which they contribute sense of a given place.

Sri Lanka is inherited with unique, historically evolved built environments that manifest culture and values of its people. Even though studies are abundant on specific historic places, their architectural significance, cultural landscapes, etc., not many attempts have been made so far to study socio-spatial attributes that sustained their attachment with the society. This study will be of benefit to the archaeological conservators, planners, urban designers, and the others, involved in maintaining such places and formulating pro-active strategies to sustain their sense of place.

\section{Literature Review}

The Latin term 'Genius Loci' has long been used to name the psycho-spatial quality experienced by people in their inhabiting places (Semon, 2014). It has evolved as the sense of place and mostly found in scholarly work in architecture, planning, urban design, and landscape studies. Sense of place is more meaningfully studied (eg: Cross, 2001; Relph, 1976; Canter, 1996) with specific attention to people's attachments to physical spaces through various interactions, and their attachments to communities to gain self-identity as two separate but simultaneous aspects. Therefore, Sense of place can be understood as a complex phenomenon that combines identity, attachment and meaning of a place. David Seamon (2012) observed that sense of place had been approached in scholarly work in three conceptualizing traditions;

i. Phenomenological Research - Examines experiential aspects of sense of place, evoke as both positive and negative qualities of human experience.

ii. Empiricist - Analytic Research - Measures sense of place in predetermined scales and criteria and correlates respondent's degree of sense of place, by means of interviews, questionnaires, etc.

iii. Social Constructionist Research - Studying the eternal human bonding with their history and culture and the conduct of different understanding of the same place's meaning at different periods throughout the history of the place. 
In a phenomenological approach Norberg-Schulz explained Genius Loci, describing the sense of place as a sum of all physical as well as symbolic values in nature and the human environment (cited in Seamon, 2012). Edward Relph's (1976) placeness and placelessness is widely known adopter of this approach. Canter (1977 and 1996) adopted a technical approach in understanding a place as an 'action setting', consisted of three tangled dimensions; the physical form, activities and imaginations. A large number of empirical works can be observed in the 'environment-behavior' stream of studies that attempted to identify sense of place and the related socio-psycho-spatial aspects of places through quantitative approaches. Lefebvre's (1991) space production ideology was adopted by many subsequent authors such as the Soja (1996), Agnew (1987) to discuss the sense of place more as an evolving socio-political phenomenon.

Although these theories and concepts provide insights on complexities of places, they have dealt less with the physical constituents that really matter for the planners, urban designers and other professionals, those who legitimately involved in planning and designing of spaces to enhance sense of place. Among limited work found in this regard, Jang Ghel's (2011) "three types of outdoor activities" (necessary activities, optional activities and social activities); outdoor activities depend on exterior physical conditions of the space 'between buildings' shed light on the important constituents of the physical environment. The 'necessary' and 'optional' activities provide the ambience and cohesion required in 'social' activities, which is crucial for place identity, attachments, and the development of sense of place.

A great majority of the studies that justified the presence of 'informal' interventions in 'formal built environments' have either focused on the 'criticalities' that forced them out of place (eg: Douglas, 1966) or attempted to develop a critical dialectic, but with a sympathetic understanding within planners and designers (eg: Perera, 2009).

Bennett's systematics was adopted by David Seamon (2012) to explain place, exploring people - place relationship in 'triadic' (three-ness). Seamon identified Geographical ensemble, People-inplace and Genius Loci as the three dimensions of a place. He further explained that these three dimensions engage in six different modes to identify a place by its inhabitants. The six triads are; Place Interaction, Place Identity, Place Creation, Place Intensification, Place Realization \& Place Release.

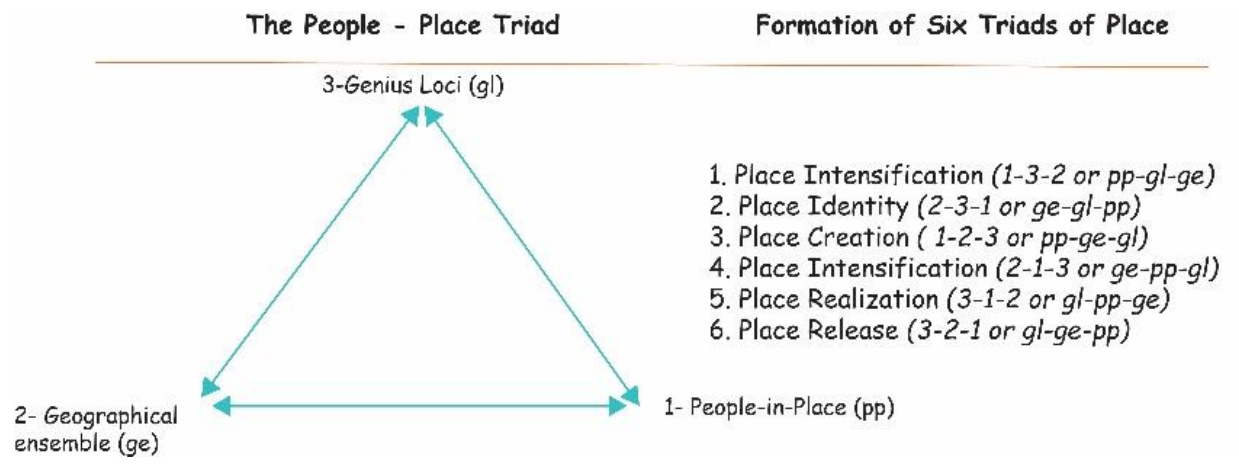

Figure 1: The three dimensions of a place (Source: David Seamon, 2012)

Seamon's approach to identity of place through six-triads, shows a high potential to examine the contribution of the temporary assemblage towards sense of place for three main reasons. The first is its phenomenological approach which is more appropriate to study a socio-spatial and psycho-spatial attributes such as sense of place. The second is its analytical process which supports a detailed scientific study of a qualitative aspect of the built environment. The third is the possibilities that it provides to account for physical ensemblement such as the temporary strictures, stalls, displays, etc., which is the subject matter of this study.

\section{The Objective}

The main objective of the study is to enable an analytical understanding of the role of the elements which can be identified as 'temporary assemblage' because of their essentially non-incorporation in the 'formal' and dominant architecture of a place. They include sheds, trade stalls, lay-on of goods for sale, extended shelters, etc., placed amidst permanent buildings and other formal spatial arrangements in cities, streets, and other urban settings. Since the widely spread critique has focused on historically significant, conserved built environments, a living example where the impact of temporary assemblage on formal architecture of 
the place is far more evident has been resort for the study. Aluth-Nuwara Devalaya has been considered a good candidate in this regard.

\section{Aluth Nuwara Devalaya}

Aluthnuwara Devalaya, situated at the boarder of Kegalle-Kandy district of Sri Lanka, in Mawanella, Hingula - Hemmathagama main road, has a history of more than seven hundred years dating back to Dambadeniya period (1267- 1301 AC), and said to have built by King Panditha Parakaramabahu II (Malimage, 1996). The place is a living monument and annually patronized by more than hundred thousand pilgrims. The crowds are mostly seen during the Asela Perahera festival (July-August) season, but in any given day the place has is visited by more than hundred visitors, both devotees and sightseers.

The formal built environment of this sacred place is a historically evolved arrangement symbolizing the local culture, societal values and religious influences in its physical setting. The main building, the palace of the deity Dedimunda, is located at a higher elevation towards the center of the premises and resembles unique Kandyan style architecture. The palace is accessible through Udu-Veediya (the upper street) from the East end entrance and Yati-Veediya (the lower street) from the West end of the premises. Both streets are flanked by temporary structures assembled by street vendors, advertising materials, colorful pandol structures, and sign boards built into the formal setting of the place. The temporary stalls have been fulfilling the situational needs of visitors such as flowers, fruits, garlands which are generally offered at the temple as well as the souvenirs, local sweets and toys, bought by visitors on their way back. Since the permanent formal architecturalarrangement of the place of Devalaya does not provide space for vendors of these goods, the vendors have resort to space within temporary structures built on either sides of the streets in-order to facilitate their interactions with visitors.

\section{The method}

The study preferred qualitative analysis, because of the nature of the matter in focus; i.e.; sense of place, which may not necessarily be captured fully and effectively through quantitative methods.

Seamon's six triad method is employed to analyze the situation in this environment. Thus, the study prepositions that the six place-based triads, namely, the Interaction, Identity, Creation,Intensification, Realization and Release, are the means through which the inhabitants demonstrate 'sense of place'. Hence, the paper progresses as an exploratory analysis of the six-triads, observable in the making and the continuation of the current state of operations at Aluth-Nuwara Devalaya premises. The three triadic components in the original studies have been adapted into the study as 'Built Environment' (Geographic Ensemble), 'Visitors' and 'Vendors' (People-in-Place) and the 'experienced quality of the space' (Sense of Place).

The temporary assemblages are built into the existing formal physical environment and the inhabitants' experience of the place is a composite of both the formal and informal assemblage. The contribution of the temporary interventions towards sense of place is studied as a comparative situation analysis. This analysis compares the current situation that accompanies temporary interventions, and the hypothetically constructed situation where no temporary interventions in the formal built environment. The current situation is documented in the form of sketch maps prepared based on the author's observations at site, on the physical arrangement and the peoples' behavior in them. The hypothesized situation is documented in the same form, but expecting a 'rational', 'objective oriented' behavior of the inhabitants at a time that temporary assemblage is not there within the premises.

A systematic field reconnaissance was carried out in the form of close observations of the visitors and the stall keepers of the place. Since the behavioral pattern of 'place users' is the focus of the Bennett's triad study, the paths and routes, place specific actions, attractions and distractions caused by specific objects of place are the 'units of observation' in this study. They were recorded using photographs, sketch diagrams and field notes. These sketches and maps were analyzed based on the conceptual framework formed out of the Bennett's six-triads, to draw the conclusions in the study.

\section{The Triad Analysis}

The three designations of the three impulses were identified as 'six conditions of identity of place', depending on the position of genius loci.

1) Place Interaction (1-3-2 or pp-gl-ge) 
From one end the visitors (people-in-place) - observes the sense of place - offered by the overall composition of the physical environment, for which they express a certain behavior within the premises. The devoted visitors enter into the premises with the intension of offering to deities and therefore, are looking for a commodity (flowers, fruits, and other goods to offer at the temple) that are commonly available in similar settings.

From the other end the vendors (people-in-place) - sense the opportunities and the conditions offered by the physical environment and position themselves in it as appropriate.Vendors possess those commodities that the devoted visitors are looking for, and they are looking for an opportunity to exchange such commodities for money.

The devoted visitors are aware that the commodities are available in this place and they sense that it is legitimate to purchase at this location. Vendors know the commodities can be given at a good price at this location and they sense it is legitimate to offer them at this location. Both parties' sense that legitimacy in the place.

Vendors make use of the space offer (pathways) and arrange to exhibit their commodities. Such arrangement is the 'temporary' structures that appropriated and facilitated the interactions between the visitors and the Vendors. Without this assemblage the place could have been too formal and thus, wouldn't have been facilitating the inhabitants sensing of the place (Figure: 2).

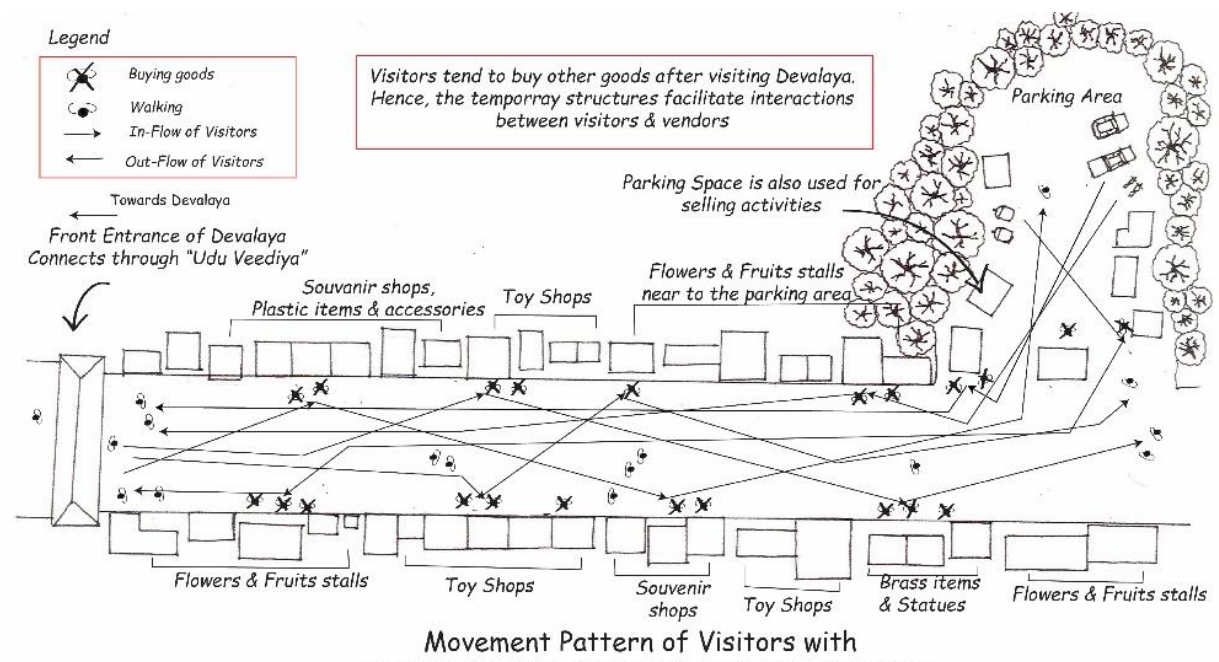

Temporary assemblages along "Udu - Veediya"

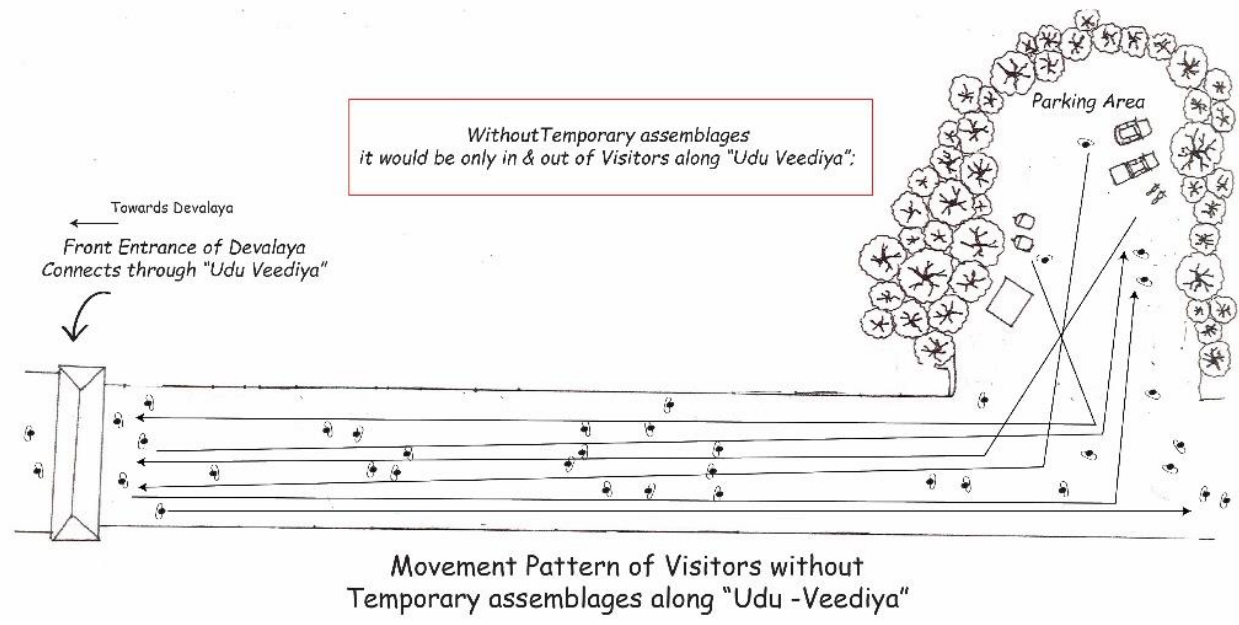

Figure 2: How temporary assemblages make interactions \& change the behavior pattern of the visitors (Source: Compiled by Author)

2) Place Identity (2-3-1 or ge-gl-pp)

The two access roads, pathway and entrances are designed to enter users to Devalaya; from Temple road through "Udu-Veediya" and from Mawanella-Aluthnuwara road through, "Yati-Veediya". B0th paths are 
flanked by the stalls of the vendors who offer the said commodities to the visitors and the unique character of temporary stalls, the commodities; flowers, fruits and other intangible elements like the fragrance of flowers, incense sticks, smell of fruits and colors of the temporary stalls provide a character that is sensed by the visitors. Those attractions modify the behavior of the devotees (Figure 3).

In a situation where the vendors' stalls were not present the physical environment would have been plain and the path of the visitors could be straight forward towards the main Devalaya, because there will be no reason for them to deviate from the straight path (Figure 4). This order within the physical environment and the sense of place caused by that provide cues and enable the users to gain sense of place to behave in it.

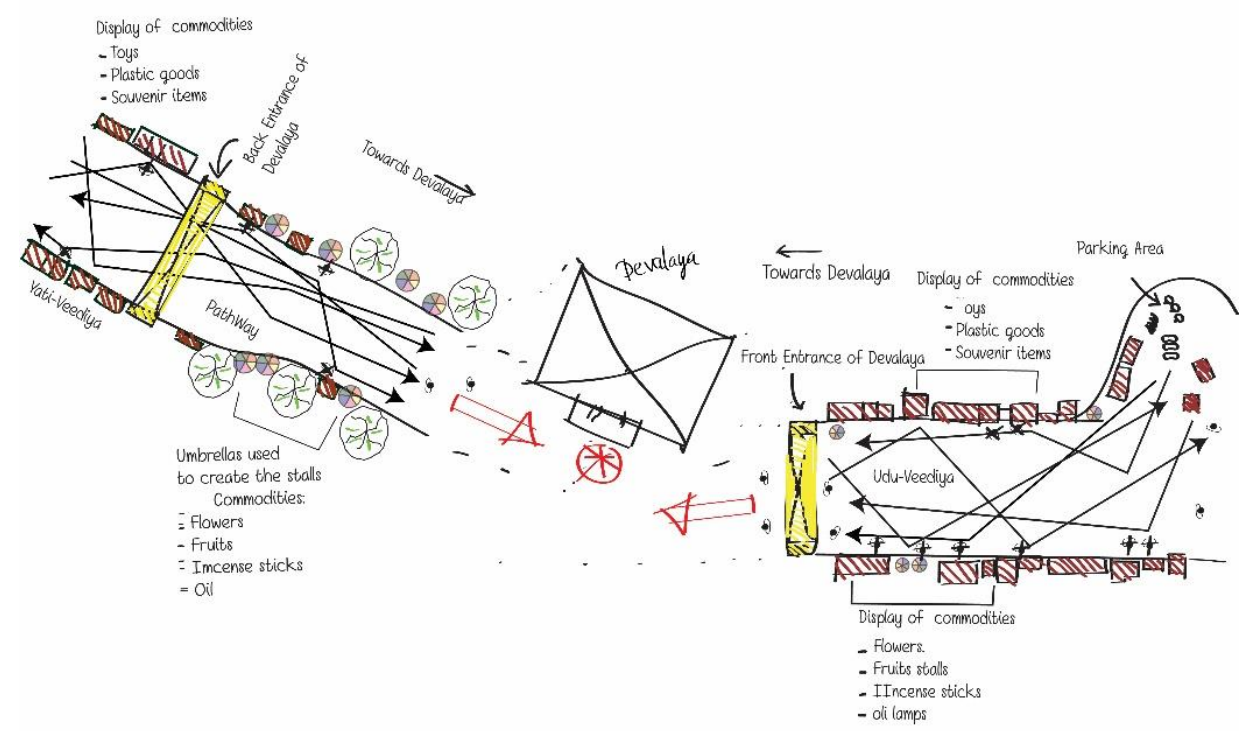

Figure 3: Two Access roads of Devalaya flanked with stalls (Source: Compiled by Author)
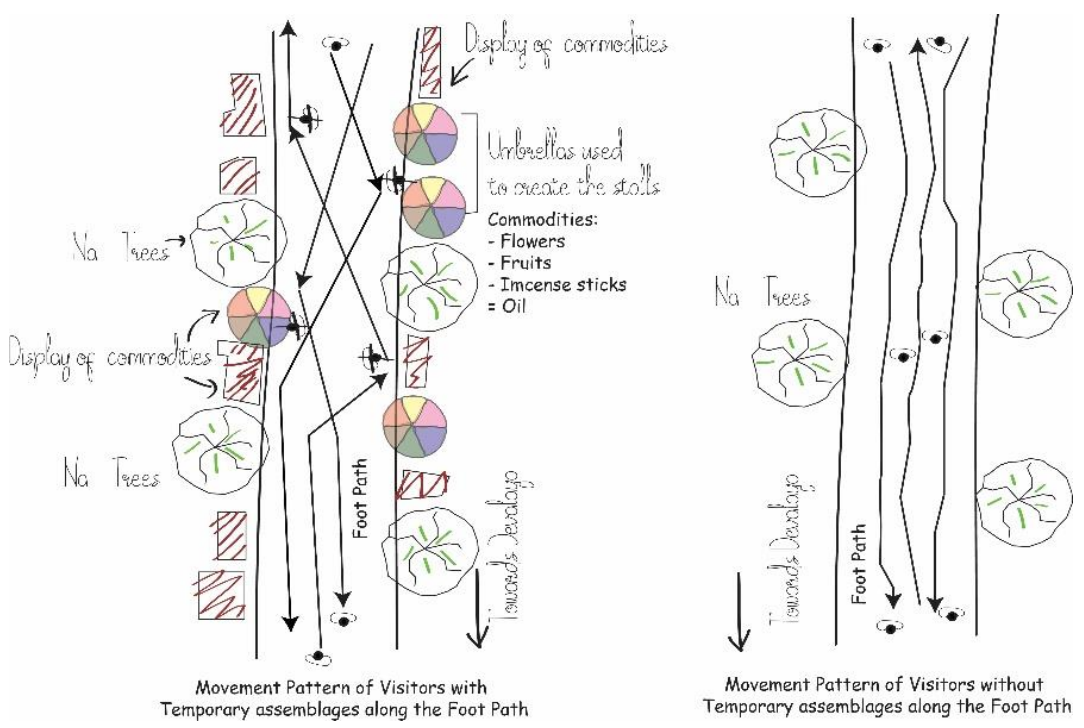

Movement Pattern of Visitors without Movement Pattern of Visitors without
Temporary assemblages along the Foot Path

Figure4: Temporary interventions attracting \& modifying the behavior patterns (Source: Compiled by Author)

\section{3) Place Creation (1-2-3 or pp-ge-gl)}

The visitors (mainly the pilgrims) are looking for commodities (flowers, fruits, etc.) to be offered at the shrine and the vendors are ready to offer such commodities. The formal physical environment of the Devalaya premises does not build a space for that interaction and therefore, the vendors' shape the exiting setup by erecting temporary stalls occupying the side spaces of the pathways. 
Under such shaping the physical environment of the premises is composite of both formal, permanent composition and non-permanent, less dominant and more informal assemblage built into the first. The temporary-nature of the second is characterized the simplicity, flexibility and the non-conformity with the architecture of the dominant strictures. The informality is enhanced by the flowers, fruits and other commodities and non-lasting materials, umbrellas, etc., of the shelters along the pathways.

The visitors can sense the formality of the sacred elements of the Devalaya, which is their main attraction, in contrast to the informality, variety and versatility associated with the temporary assemblage. The vendors also sense the restrictive nature of the formal environment and thus, the need to reshape it for better interactions with visitors, for which reason they assemble the structures (Figure 5).
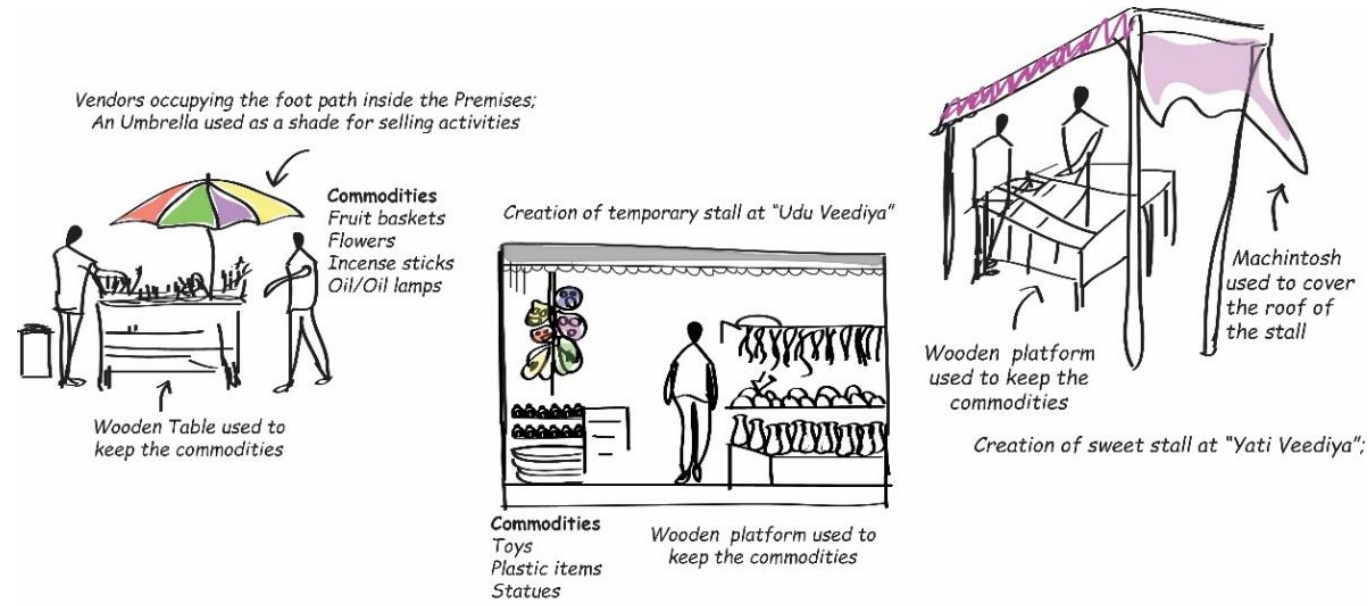

Figure 5: Informal creation of Temporary stalls in Aluth-Nuwara

\section{4) Place Intensification (2-1-3 or ge-pp-gl)}

The presence of "Na Trees" along the pathways inside Devalaya premises and parking area at "UduVeediya" located adjacent to the sacred area, are supportive constructions and designs that offer vendors to create 'places' and intensify in their presence within the premises. At the same time the presence of stalls amidst formal permanent settings in both paths ways, the people change their behavior, which otherwise would have been straight forward as stated under (2) Place Identity. Because of the presence of these vendors and their commodities the visitor behavior has now deviated from that formalness and added with some informality. This informal behavior itself has become part of the place, which otherwise could have been regimented and less of bustle. The bustle is what enables the visitors and vendors to sense and find comfort in this supposedly sacred formal environment (Figure 6 - contract people behavior (paths) between two situations). In this manner the temporary assemblage evidently facilitates intensification of the sense of place in its inhabitants.

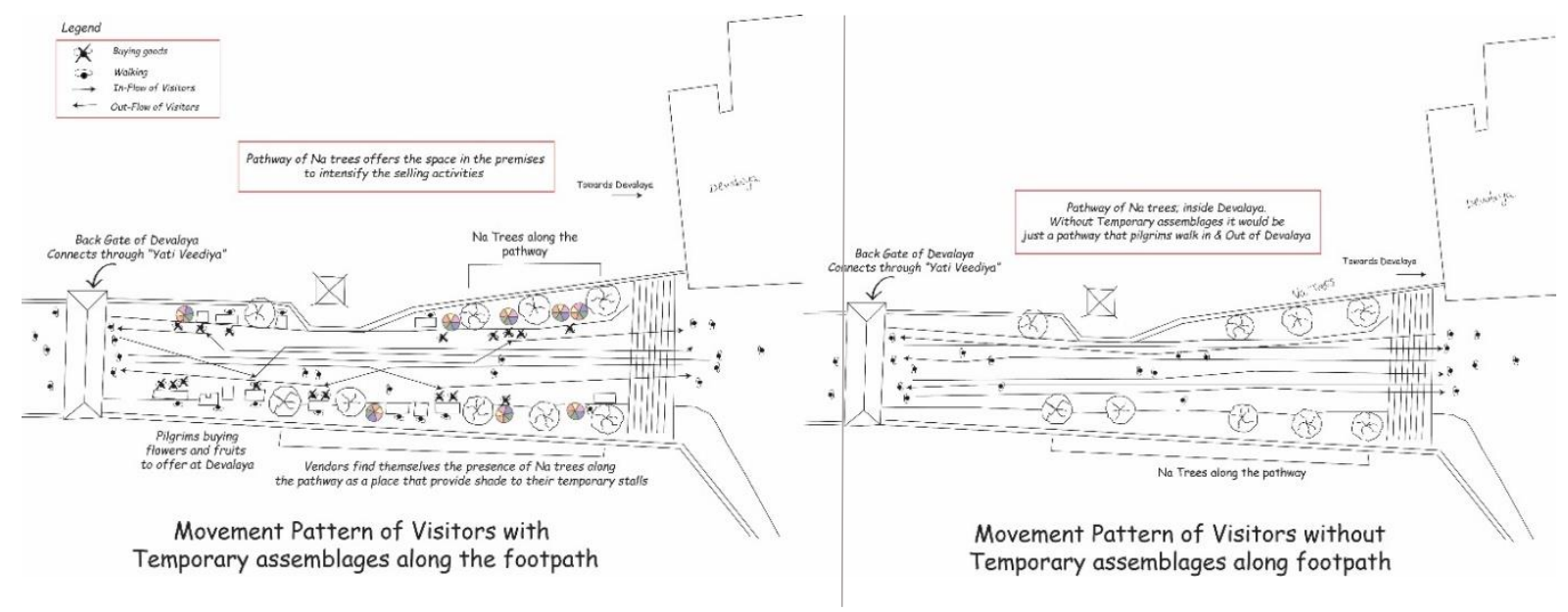

Figure6: Supporting design of Na-trees along the footpath intensifies selling activities

(Source: Author) 
5) Place Realization (3-1-2 or gl-pp-ge)

The permanent architectural arrangement of the Devalaya premises projects a dominance and formality through which the inhabitants sense the sacredness of the place. But the low scale temporary structures of the place along with the other sensory aspects such as the fragrance, colors and textures of the commodities dilute and bring down such dominant sacredness to sense the place in a more intimate human scale.

The inhabitants experience a desired mix of formal-informal behaviors the sacred place. With a thorough sense of the place developed in this manner, both the visitors and vendors interact with the place and with each other and such interactions result in a physical environment, which further enhances the identity and the realization of the place.

The visitors' place realization is supported by the arrangement of the physical setting. By organizing the temporary structures on either side along the pathways to the center, the visitors are enabled to continue their progression towards their final destination, i.e. Devalaya without disturbances. The vendors' realization is supported by the same arrangement where they make close contacts with visitors along their progression towards Devalaya.

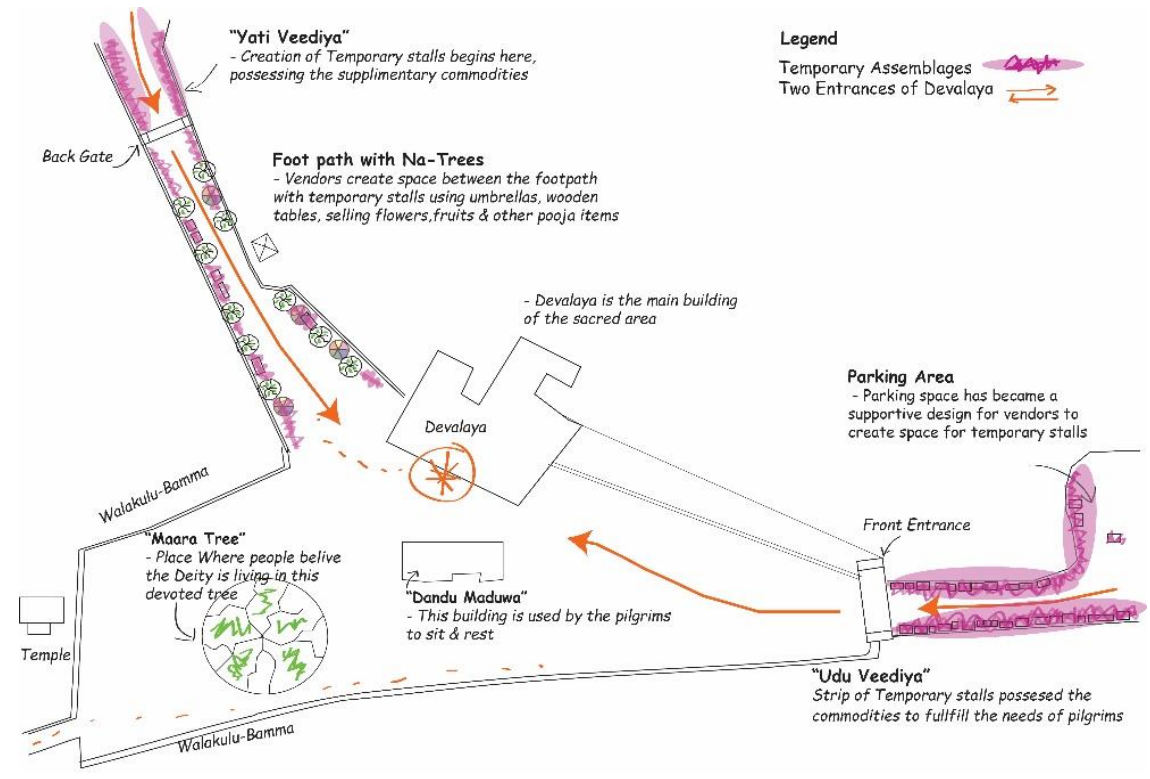

Figure 7: Composition of formal \& informal arrangement of Aluth-Nuwara Devalaya (Source: Compiled by Author)

\section{6) Place Release (3-2-1 or gl-ge-pp)}

Visitors and the vendors sense the place with a mix of dominant formalities and the subdued informalities, to guide a certain mutually agreed behavior naturalized into the premises. Such naturalized behaviors reconfirm and recreate the physical environment of the place.

The recreated environment enables the visitors and vendors their desired types of behavior, and thereby a release in place. Temporary interventions are freely experienced within the premises as a part of sacred area. Even though Devalaya is the final destination of the journey, the flower and fruits stalls, plastic items, toys, accessories, souvenir items, food stalls etc., lined along the pathways are no obstacle to their journey. Instead, they freely fulfill their needs along the path. Therefore, both the visitors and vendors find satisfaction and pleasure because it allows them to make interactions through the place.

Comparing the two situations; with and without temporal activities, it can be noted that there is a high interaction with the temporary stalls before visiting Devalaya. After visiting Devalaya, the visitors interact with other stalls like; toy shops, plastic good stalls, souvenir shops etc... In the situation where without temporary activities would be a straight movement of visitors from two access roads to Devalaya. No any stoppings or interactions throughout the journey. Without these temporary assembles, it would 
be only the interaction between Devalaya and visitors. Hence the presence of temporary assembles aggrandize the quality of place in Aluth-Nuwara (Figure 8).

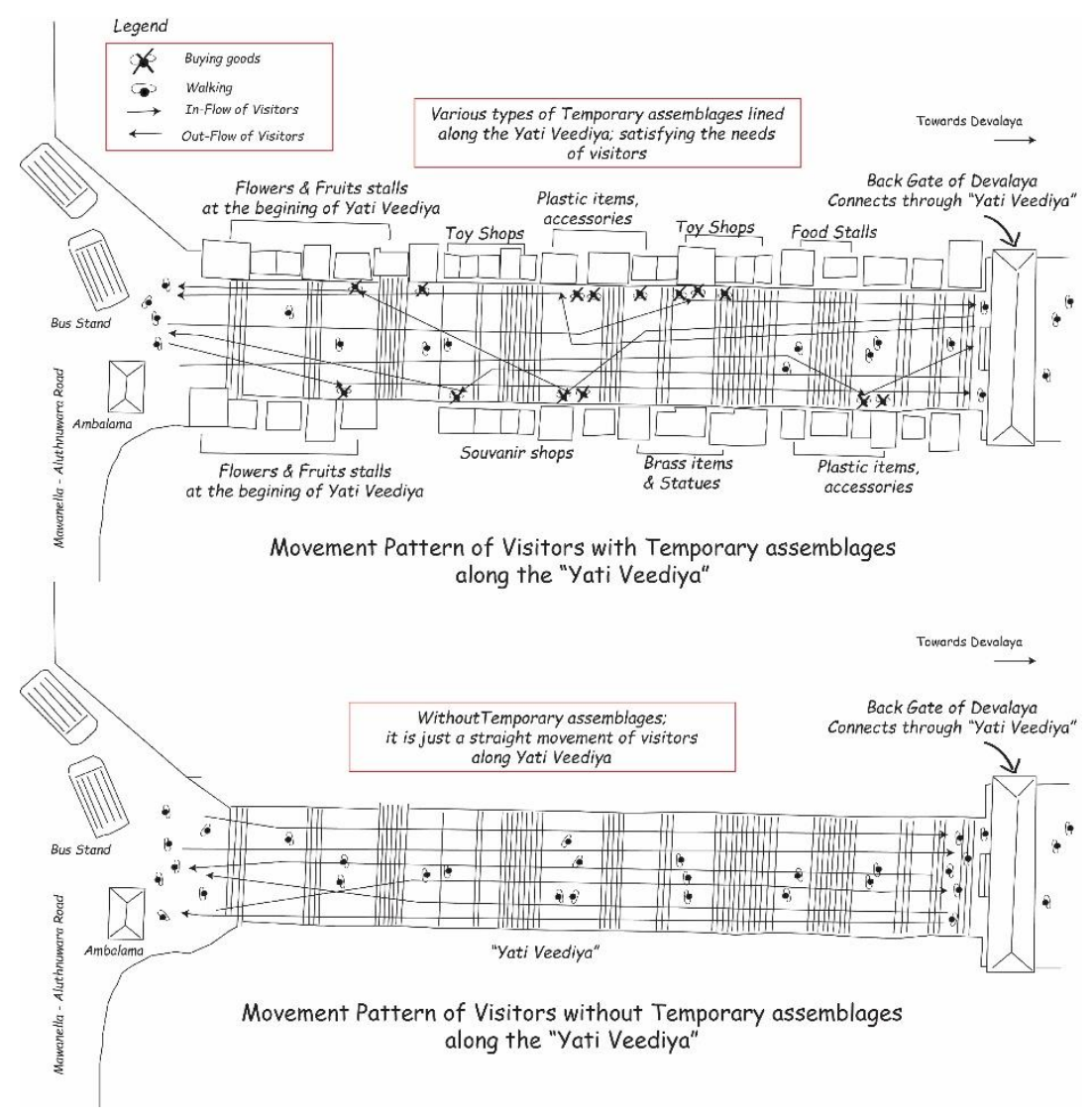

Figure 8: Changes of the activity patterns of visitors; with \& without temporary interventions (Source: Compiled by Author)

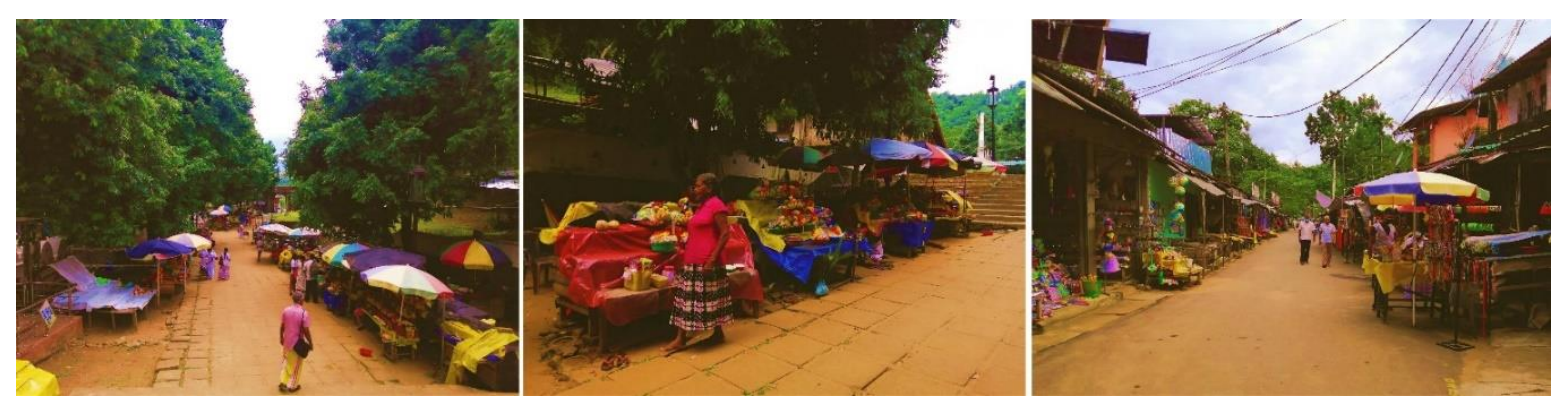

Figure 9: Temporary assemblages lined at the paths of Aluth-Nuwara Devala area (Source: Author)

\section{Conclusion and Recommendation}

Sense of place is still vaguely defined and less firmly established; despite a large number of studies those adopted different approaches, theoretical propositions, research traditions. Most of these works are limited in explaining the concept in a manner that it can be progressively and effectively strategized in spatial planning and urban design.

However, the experienced environment is an essential component in attributing sense of place in its inhabitants. The experienced environments are results of both the dominant orchestration of permanent physical elements framing formal spaces and temporary assemblage built in to the same for shaping the formality into informal vitality. Yet it is a matter of debate as to whether the temporary assemblage should be accommodated within formal conserved built environments such as historic quarters of cities, ceremonial streets, and sacred areas, and what impact such temporary interventions may 
have on sense of place. Amidst this debate, this study attempted to analyze the impact of temporal assemblage on a historic built environment, employing Seamon's six-triad of place identity, in which sense of place is one out of the three impulses.

The study showed the manner in which the temporary assemblage in Aluthnuwara facilitated interactions among visitors, vendors, and Devalaya premises, and enabled smooth and more humanistic operations in site. Vendors' interventions with stalls, unique commodities, visual structures, color, and smell create the place with the presence and thereby inspire the place interactions of the visitors. Visitors, in turn, realize the place with their compliance and intensification of the spatial arrangement. These mutual interactions are the means thorough which the sense of place in its inhabitants is continuously vitalized and revitalized.

This study has demonstrated the likely change in the behavior of the visitors of a place comparing two situations; when temporary assemblage is in place and when it is not there. It could sufficiently explain that temporary assemblage impacts the sensing of places, not only by their presence in place but also by changing inhabiting (people's behavior) of the place. As a method the use of six-triads of identity of place provided a sound basis to study the sense of place, and it can be effectively used to guide qualitative understanding required in decision making, environmental policy and sustainable design.

The study is concentrated only on one historical sacred place of the local context. It is obvious that this study is not adequate to generalize the findings to other types of built environments. Other dimensions of temporary assemblage in formal environs, where space economics, space optimization, spatial movements, etc., also need to be given equal consideration. It may also be argued that the findings are biased to the positive impact of temporary assemblages towards sense of place. Yet, in a context where limited studies regarding the assessing of sense of place, this study serves as a step towards a better understanding and further help in guidance for decision making, environmental policy and sustainable design.

\section{References}

A.Rapoport, 1977. Human Aspects of Urban Form: Towards a Man-Environment Approach to Urban Form and Design. Oxford: Pergamon Publishing. Agnew, J., 1987. Place and Politics: The Geographical Mediation of State and Society. Boston: Boston (Mass.) : Allen and Unwin.

Bertino, G. et al., 2019. Framework Conditions and Strategies for Pop-Up Environments in Urban Planning. Sustainability.

Canter, D.V., 1977. The Psychology of Place. Palgrave Macmillan.

Canter, D., 1996. The Facets of Place. Hantshire: Dartmouth Publishing Company.

Cross, J.E., 2001. What is Sense of Place? In Headwaters Conference,Western State College., 2001.

Douglas, M., 1966. Purity and Danger: AN ANALYSIS OF CONCEPT OF POLLUTION AND TABOO. Routledge.

DOVEY, K., WOLLAN, S. \& WOODCOCK, I., 2012. Placing Graffiti: Creating and Contesting Character in Inner-city

Melbourne. Journal of Urban Design, p.22.

E.C.WRIGHT, 2009. “THERE'S NO PLACE LIKE NEW ORLEANS”:SENSE OF PLACE AND COMMUNITY RECOVERY IN

THE NINTH WARD AFTER HURRICANE KATRINA. Journal of Urban Affairs, pp.615-34.

Furner, J., 2004. Conceptual Analysis: A Method for Understanding Information as Evidence, and Evidence as Information. Archival Science, pp.233-65.

Gehl, J., 2010. Cities for People. Island press.

Ghel, J., 2011. Life Between Buildings:using Public space. Island Press.

Graham, H., Mason, R. \& Newman, A., 2009. Historic Environment, Sense of Place, and Social Capital.

Jecobs, J., 1961. The Death and Life of Great American Cities.

JIVE'N, G. \& LARKHAM, P.J., 2003. Sense of Place, Authenticity and Character: A Commentary. Journal of Urban Design, pp.67 - 81 .

Lefebvre, H., 1991. The Production of Space. Oxford, England: Blackwell.

Malimage, A., 1996. Watha Dunu Dew.

Mankus, M., 2015. Tactics for Temporary Uses of Buildings and Spaces in Architecture. pp.132 - 140.

Meetiyagoda, L., 2018. Pedestrian Safety in Kandy Heritage City, Sri Lanka: Lessons from World Heritage Cities. Sustainable Cities and Society, pp.301 - 308.

Najafi, M. \& Shariff, M.K.B.M., 2011. The Concept of Place and Sense of Place In Architectural Studies. International Journal of Social, Behavioral, Educational, Economic, Business and Industrial Engineering, p.7.

Norberg-Schulz, C., 1980. Genius Loci: Towards a Phenomenology of Architecture. 
Pathinayaka, A.D. \& Wijesundara, J., 2015. Imaging Cities; Social Perception and Physical Composition; Case study of Pettah, Colombo. International Journal on Urban Environments, p.14.

Perera, N., 2009. People's Spaces: Familiarization, Subject Formation and Emergent Spaces in Colombo. SAGE Journals, Volume 8(Issue 1), pp.51 - 75.

Relph, E., 1976. Place and placelessness. London: Pion Limited.

S.K.Hawke, 2010. Belonging: the contribution of heritage to sense of place. In Changing World,Changing Views of Heritage:heritage and social change. Dublin, 2010. ICOMOS International Secretariat.

Seamon, D., 2012. Place, Place Identity, and Phenomenology: A Triadic Interpretation Based on J.G. Bennett's

Systematics. The Role of Place Identity in the Perception, Understanding, and Design of Built Environments, pp.3 -21. Semon, D., 2014. Sense of Place. International Encyclopedia of Geography: People,the Earth, Environment, and Technology.

Shinbira, I.A., 2012. Conservation of the Urban Heritage to Conserve the Sense of Place, a Case Study Misurata City, Libya. American Transactions on Engineering \& Applied Sciences, p.12.

Shuhana Shamsuddina, N.U., 2008. Making places: The role of attachment in creating the sense of place for traditional streets in Malaysia. Habitat International, pp.399-409.

Skubic, M. et al., 2002. Qualitative Analysis of Sketched Route Maps:Translating a Sketch into Linguistic Descriptions. p.7.

Soja, E.W., 1996. Thirdspace: journeys to Los Angeles and other real-and-imagined places. Mass: Blackwell.

Topcu, K.D. \& Topcu, M., 2012. Visual presentation of mental images in urban design education:cognitive maps.

Procedia - Social and Behavioral Sciences, pp.573 - 582.

Wijesundara, J., 2015. Re-invigorating the Spirit of Place of Kandy:Urban Design and City Planning Strategies. p.11. Wijesundara, J. \& Wijekoon, N., 2017. Transitory Urban Interventions for Effective Place making in Shopping Streets: Case of Pettah in Sri Lanka. Cities People Places, pp.10-25.

Yatmo, Y.A., 2008. Street Vendors as 'Out of Place' Urban Elements. Journal of Urban Design, Volume13, pp.387 - 402. 